\title{
A reanalysis of cancer mortality in Canadian nuclear workers (1956-1994) based on revised exposure and cohort data
}

\author{
L B Zablotska*,1, R S D Lane ${ }^{2}$ and P A Thompson ${ }^{2}$ \\ ${ }^{1}$ Department of Epidemiology and Biostatistics, School of Medicine, University of California, San Francisco, CA 94118, \\ USA and ${ }^{2}$ Directorate of Environmental and Radiation Protection and Assessment, Canadian Nuclear Safety Commission, \\ Ottawa, ON K1P 5S9, Canada
}

Background: A 15-country study of nuclear workers reported significantly increased radiation-related risks of all cancers excluding leukaemia, with Canadian data a major factor behind the pooled results. We analysed mortality (1956-1994) in the updated Canadian cohort and provided revised risk estimates.

Methods: Employment records were searched to verify and revise exposure data and to restore missing socioeconomic status. Excess relative risks per sievert (ERR/Sv) of recorded radiation dose and $95 \%$ confidence intervals (Cls) were estimated using Poisson regression.

Results: A significant heterogeneity of the dose-response for solid cancer was identified ( $P=0.02)$, with 3088 early (1956-1964) Atomic Energy of Canada Limited (AECL) workers having a significant increase (ERR/Sv $=7.87,95 \% \mathrm{Cl}: 1.88$, 19.5), and no evidence of radiation risk for 42228 workers employed by three nuclear power plant companies and post-1964 AECL (ERR/Sv $=-1.20,95 \%$ $\mathrm{Cl}:<-1.47,2.39)$. Radiation risks of leukaemia were negative in early $A E C L$ workers and non-significantly increased in other workers. In analyses with separate terms for tritium and gamma doses, there was no evidence of increased risk from tritium exposure. All workers had mortality lower than the general population.

Conclusion: Significantly increased risks for early AECL workers are most likely due to incomplete transfer of AECL dose records to the National Dose Registry. Analyses of the remainder of the Canadian nuclear workers (93.2\%) provided no evidence of increased risk, but the risk estimate was compatible with estimates that form the basis of radiation protection standards. Study findings suggest that the revised Canadian cohort, with the exclusion of early AECL workers, would likely have an important effect on the 15-country pooled risk estimate of radiation-related risks of all cancer excluding leukaemia by substantially reducing the size of the point estimate and its significance.

Ionising radiation is a known human carcinogen (International Agency for Research on Cancer (IARC), 2000, 2012) and has been studied extensively in various population groups, including nuclear workers occupationally exposed to radiation. In Canada, radiation doses are measured by licensed dosimetry services and submitted to both the National Dose Registry (NDR) and to employers. The NDR collects and records radiation exposure and dose data for all exposed workers in Canada from 1951 (with some records going back to 1944) ((National Dose Registry (NDR), 2007). The first
Canadian study of nuclear workers was based on one facility (Atomic Energy of Canada Limited (AECL)) and used radiation doses provided directly by AECL (Gribbin et al, 1993). Analysis was based on workers monitored between 1956 and 1980, and doses for workers exposed before 1956, for which records had been destroyed in the February 1956 fire, were reconstructed for those still in employment in 1956. Study data were included in the pooled analysis of mortality of nuclear workers from three countries (Cardis et al, 1995). Several later NDR-based studies

*Correspondence: Dr LB Zablotska; E-mail: lydia.zablotska@ucsf.edu

Received 10 June 2013; revised 2 September 2013; accepted 3 September 2013;

published online 14 November 2013

(c) 2014 Cancer Research UK. All rights reserved 0007-0920/14

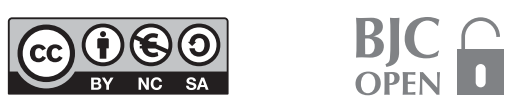


included radiation-exposed workers from a variety of occupational settings and are outside the focus of this paper (Ashmore et al, 1998; Sont et al, 2001). The most recent study of Canadian nuclear workers (Zablotska et al, 2004) included post-1956 workers from AECL, and workers from Hydro-Québec (HQ), New Brunswick Power Corporation (NB) and Ontario Hydro $(\mathrm{OH})$, all of which started monitoring after 1956 . The study reported a sizeable, although statistically nonsignificant, increased risk of solid cancer mortality (excess relative risk per sievert $(\mathrm{ERR} / \mathrm{Sv})=2.80,95 \% \mathrm{CI}$ : $-0.038,7.13)$. Table 1 presents the chronology of Canadian studies, as well as international studies which included Canadian nuclear workers, and highlights this important change of the source of radiation dose information, which occurred in the late 1990s.

The data from the last Canadian study (Zablotska et al, 2004) (hereafter referred to as 'the original Canadian study') were provided to the International Agency for Research on Cancer (IARC) for the 15-country pooled mortality analysis (Cardis et al, $2005,2007)$. This pooled study showed statistically significantly increased risks per unit of occupational ionising radiation dose for mortality from solid cancer and from all cancers excluding leukaemia (Table 2, models 1-3), which were three times as high as the ERR estimate for solid cancer mortality in Japanese atomic bomb (A-bomb) survivors exposed to higher doses $(\mathrm{ERR} / \mathrm{Sv}=0.32$, 95\% CI: 0.01, 0.50, males exposed at age 35 years) (Cardis et al, 2007). In the pooled analysis (Cardis et al, 2007), Canadian workers had the highest cancer radiation risk estimates among the 15 countries (Table 1, study 6) and were a major factor behind the significant pooled results. None of the other 14 country cohorts individually had significantly raised cancer mortality risk estimates. The exclusion of the Canadian workers ( $4 \%$ of the sample) from the pooled analysis changed the findings to statistically nonsignificant with a reduction of the pooled risk estimate by $40 \%$ (Table 2, model 4) (Cardis et al, 2007). The apparent difference in the results between the Canadian and the 15-country studies attracted a lot of attention and raised questions as to the data and analytical validity (Wakeford, 2005; United Nations Scientific
Committee on the Effects of Atomic Radiation (UNSCEAR), 2008; Wakeford, 2009; Boice, 2010).

Radiation risk estimates for leukaemia were not significant for Canada in the 15-country study (Cardis et al, 2007). In contrast, previous Canadian studies (Gribbin et al, 1993; Cardis et al, 1995; Zablotska et al, 2004) and the A-bomb and other studies (National Research Council (NRC), 2006) reported significantly raised radiation risks for leukaemia. A recent independent study of UK radiation workers, which did not contribute in its entirety to the 15 -country study, reported significantly increased risks of mortality from leukaemia and from all cancers excluding leukaemia (ERR/ $\mathrm{Sv}=1.712,90 \% \mathrm{CI}: 0.06,4.29$ and $\mathrm{ERR} / \mathrm{Sv}=0.275,90 \% \mathrm{CI}: 0.02$, 0.56 , respectively; Muirhead et al, 2009).

To better understand the radiation risks of Canadian nuclear workers, the Canadian Nuclear Safety Commission (CNSC) initiated a study with the following objectives:

1. Create a revised cohort based on a detailed review of employment and dose records, various corrections and improvements, and updated socioeconomic status (SES) information for nuclear workers.

2. Assess cancer risks for Canadian nuclear workers from wholebody radiation exposures based on the revised cohort.

3. Assess tritium-specific cancer risks for Canadian nuclear workers. (In Canada, CANDU heavy water moderated nuclear power reactors are a potential source of occupational tritium exposure for nuclear workers. No studies to date have reported tritium-specific risks for nuclear workers (Little and Wakeford, 2008)).

\section{MATERIALS AND METHODS}

Review of the differences between the 15-country and original Canadian studies. The data from the original Canadian cohort

\begin{tabular}{|c|c|c|c|c|c|c|c|}
\hline No. & Study & Reference & $\begin{array}{l}\text { Source of } \\
\text { exposure } \\
\text { information }\end{array}$ & $\begin{array}{c}\text { Cohort } \\
\text { description }\end{array}$ & $\begin{array}{l}\text { No. of } \\
\text { deaths }\end{array}$ & $\begin{array}{c}\text { Mean } \\
\text { cumulative } \\
\text { whole- } \\
\text { body } \\
\text { gamma } \\
\text { dose, mSv }\end{array}$ & ERR/Sv $(90 \% \mathrm{Cl})$ \\
\hline 1 & AECL workers & (Gribbin et al, 1993) & $\mathrm{AECL}$ & $8977 \mathrm{M}$ & 221 & 15 & $0.049(-0.68,2.17)$ \\
\hline 2 & $\begin{array}{l}\text { AECL workers in the } \\
\text { IARC 3-country study }\end{array}$ & (Cardis et al, 1995) & $\mathrm{AECL}$ & $11355 \mathrm{M}, \mathrm{W}$ & 234 & NR & $0.13(<0,2.1)$ \\
\hline 3 & NDR workers & (Ashmore et al, 1998) & NDR & $\begin{array}{l}105456 \mathrm{M} \\
101164 \mathrm{~W}\end{array}$ & $\begin{array}{l}1136^{b} \\
496^{b}\end{array}$ & $\begin{array}{c}10.6 \\
1.7\end{array}$ & $\begin{array}{c}3.0(1.1,4.9)^{\mathbf{b}} \\
1.5(-3.3,6.3)^{\mathbf{b}}\end{array}$ \\
\hline 4 & NDR workers & (Sont et al, 2001) & NDR & $\begin{array}{c}95643 \mathrm{M} \\
191333 \mathrm{M}, \mathrm{W}\end{array}$ & $\begin{array}{l}2030^{c} \\
3639^{c}\end{array}$ & $\begin{array}{l}11.5 \\
6.64\end{array}$ & $\begin{array}{l}2.5(1.1,4.2)^{c} \\
2.3(1.1,3.9)^{c}\end{array}$ \\
\hline 5 & Canadian nuclear workers & (Zablotska et al, 2004) & NDR & $45468 \mathrm{M}, \mathrm{W}$ & $474^{d}$ & 13.5 & $2.80(-0.038,7.13)^{\mathrm{d}, \mathbf{e}}$ \\
\hline 6 & $\begin{array}{l}\text { Canadian nuclear workers in the } \\
\text { IARC 15-country study }\end{array}$ & (Cardis et al, 2007) & NDR & $\begin{array}{l}15955 \mathrm{M}, \mathrm{W} \\
\text { excluding } \mathrm{OH}\end{array}$ & 204 & $N R^{f}$ & $6.65(2.56,13.00)^{f}$ \\
\hline 7 & $\begin{array}{l}\text { Canadian nuclear workers in the } \\
\text { IARC } 15 \text {-country study }\end{array}$ & $\begin{array}{l}\text { (Cardis et al, 2007) } \\
\text { (Vrijheid et al, 2007) }\end{array}$ & NDR & $\begin{array}{l}38736 \mathrm{M}, \mathrm{W} \\
\text { including } \mathrm{OH}\end{array}$ & 400 & $19.5^{f}$ & $3.60(1.03,7.27)^{f}$ \\
\hline \multicolumn{8}{|c|}{ 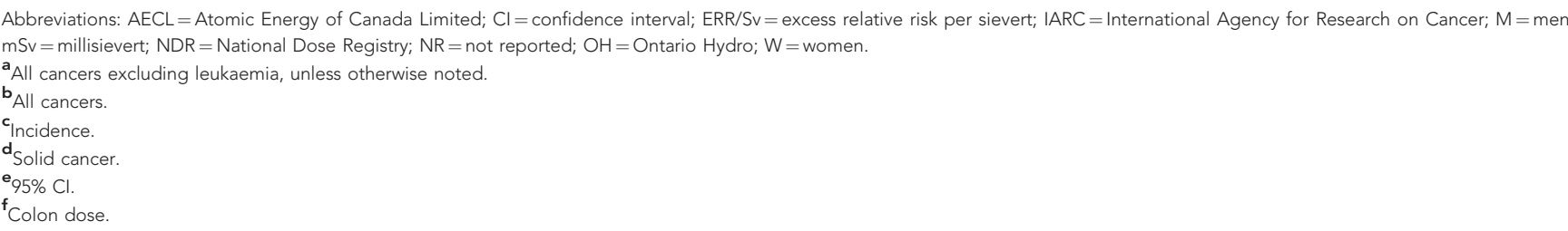 } \\
\hline
\end{tabular}




\begin{tabular}{|c|c|c|c|c|}
\hline Reference & Model No. & Model description & No. of deaths & ERR/Sv $(95 \% \mathrm{Cl})$ \\
\hline \multirow[t]{5}{*}{ (Cardis et al, 2005) } & & All cancers excluding leukaemia & & \\
\hline & 1 & Standard analysis ${ }^{a}$ & 5024 & $0.97(0.14,1.97)$ \\
\hline & & Solid cancer & & \\
\hline & 2 & Standard analysis & 4770 & $0.87(0.03,1.88)$ \\
\hline & & & No. of deaths & ERR/Sv $(90 \% \mathrm{Cl})$ \\
\hline \multirow[t]{4}{*}{ (Cardis et al, 2007) } & & All cancers excluding leukaemia & & \\
\hline & 3 & Standard analysis & 5024 & $0.97(0.27,1.80)$ \\
\hline & 4 & Standard analysis excluding Canada & 4820 & $0.58(-0.10,1.39)$ \\
\hline & 5 & Standard analysis plus $\mathrm{OH}$ & 5220 & $0.89(0.21,1.69)$ \\
\hline
\end{tabular}

study (Zablotska et al, 2004) were provided to IARC for the 15-country pooled analysis (Cardis et al, 2005, 2007). Although both studies used the same data and similar protocols for eligibility and exclusions, several potentially important differences have been identified. One difference was in the determination of those monitored $>1$ year. Based on the a priori protocol, the 15-country study excluded 13990 workers with only one annual dose record from the Canadian cohort, while the original Canadian study excluded only 7444 workers and retained the remaining 6546 workers who had monthly employment records (obtained from the nuclear facilities), which showed that they were monitored for $>1$ year. A less important difference was the use of colon doses in the 15 -country analysis, which on average were $9.1 \%$ lower compared with the recorded doses used in the original Canadian cohort study (range: $-3,33 \%$ ). Finally, in the original Canadian study, solid cancer and leukaemia mortality risk estimates with and without adjustment for SES were similar; thus workers with missing SES information were included in the analysis (Zablotska et al, 2004). In the 15-country study, according to the a priori protocol, cohorts with large numbers of workers with missing SES information were excluded from analyses of all cancers excluding leukaemia, approximately a third of the pooled cohort. The 15-country study excluded $\mathrm{OH}$ workers $(n=22769,58.8 \%$ of the Canadian cohort, SES missing for $49.7 \%$ of workers or $14 \%$ of total $\mathrm{OH}$ person-time) but retained AECL workers ( $n=11382$, SES missing for $25.7 \%$ of workers or $29 \%$ of total AECL person-time) (Vrijheid et al, 2007). Pooled radiation risk estimates with and without $\mathrm{OH}$ were significantly increased (Table 2, models 5 and 3, respectively), suggesting that the unusually high Canadian dose-related risk estimate in the 15-country study was most likely driven by AECL workers, who represented the majority of the Canadian cohort, had the longest follow-up and the highest radiation doses.

Creation of the original Canadian cohort. Formation of the original Canadian cohort is described in detail in Zablotska et al (2004). In brief, the NDR contains all available information on radiation exposure for $>500000$ workers who have potential radiation exposure (Ashmore et al, 1997). In order to be eligible for the current cohort, participants had to be monitored in a nuclear facility in Canada for $\geqslant 1$ year, registered in the NDR and had to have a minimum of identifying information to ensure reliable linkage with the death records (see below). The 1-year minimum monitoring was to avoid including individuals with very shortterm employment who often demonstrate irregular mortality patterns (Howe et al, 1988).
The first reactor at AECL came on line in 1949 but a fire destroyed AECL dose records in 1955. Hence, only employees whose monitoring started in 1956 or later were included in the cohort. The power generating companies $(\mathrm{OH}, \mathrm{HQ}, \mathrm{NB})$ all started nuclear operations after 1956. A further 188 potential subjects were excluded for irregularities in their records, leaving a cohort of 45468 for analysis (Table 3).

Revisions and updates of the original Canadian cohort and creation of the revised cohort. As our initial evaluation pinpointed an important change in exposure information for AECL workers over time (Table 1), an extensive evaluation of the AECL facility and NDR dose records and their cross-verification was initiated (Ashmore et al, 2010). This process involved careful review of dosimetric practices at AECL and the protocols for data validation, verification, storage and transfer to the NDR. We used the roster of AECL workers from Gribbin et al (1993) and the list of AECL workers from the NDR to recreate a more complete roster of workers monitored at AECL before 1981. Although it was possible to recreate the employment roster, dose files created for the Gribbin et al (1993) study have been lost. After correcting for mistakes and resolving duplicates, the resultant file of 14768 workers was linked to the NDR dose records for 1956-1980 and to the Statistics Canada mortality file created for the original Canadian study. A total of 2871 workers could not be linked to the NDR, although some had worked up to 15 years at AECL. The reasons why they do not have records in the NDR remain uncertain. It is important to underscore that these workers contributed to the first studies of AECL workers (Gribbin et al, 1993; Cardis et al, 1995) but did not contribute to the NDR-based studies (Zablotska et al, 2004; Cardis et al, 2007).

During the search of AECL dose records and their comparison with the NDR dose records, we found 505 workers who were employed before 1956 and thus were not eligible to participate in the study by Zablotska et al (2004) or Cardis et al (2007) and were excluded from the revised cohort (Table 3 ). We restored missing zero-recorded doses for 5336 workers that were not reported to the NDR between 1956 and 1970. Finally, original SES assignments were done in 2001 for $\mathrm{OH}$ workers employed at the time. We computerised job classifications at the time of hire for all $\mathrm{OH}$ workers and used this information to assign SES status of workers in the revised cohort. The details of these and other data revisions are summarised in Supplementary Table S1.

Dosimetry. The NDR database contains annual summary doses for whole-body external and internal radiation exposure for each monitored individual from each organisation where he/she was 
Table 3. Demographic and exposure characteristics of the original and revised Canadian cohorts of nuclear workers, 1956-1994

Analytical cohort

\begin{tabular}{|l|c|c|}
\cline { 2 - 3 } \multicolumn{1}{l|}{} & Original $^{\mathbf{a}}$ & Revised $^{\mathbf{b}}$ \\
\hline Original size of the cohort & 45656 & 45656 \\
\hline Exclusions & \multicolumn{2}{|l|}{} \\
\hline $\begin{array}{l}\text { Nuclear monitoring at AECL } \\
\text { before 1956 } \\
\text { Irregularities in records }\end{array}$ & 188 & 505 \\
\hline
\end{tabular}

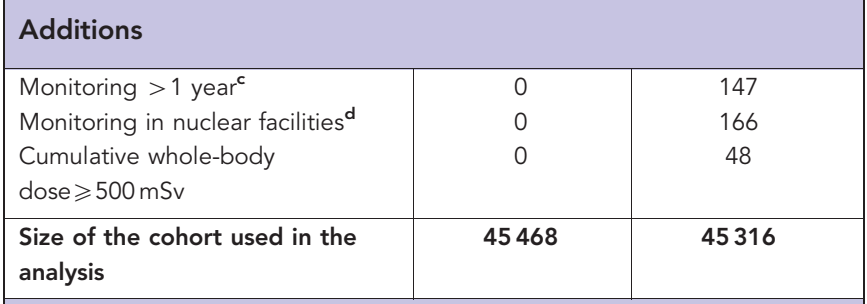

$\operatorname{Sex}(\%)$

\begin{tabular}{|l|r|r|}
\hline Male & $37735(83.0)$ & $37697(83.2)$ \\
Female & $7733(17.0)$ & $7619(16.8)$ \\
\hline
\end{tabular}

Facility (\%)

\section{AECL}

Hydro-Québec

New Brunswick Power Corporation

$16361(36.0)$

$2283(5.0)$

15937 (35.2)

2154 (4.7)

$2358(5.2)$

Ontario Hydro

$23217(51.1)$

$2154(4.8)$

Multiple facilities

1453 (3.2)

$23414(51.7)$

1453 (3.2)

\section{SES (\%)}

\section{1-Professional}

2-Other 'white collar'

3- 'Blue collar' skilled

4- 'Blue collar' unskilled

9-Unknown
$5519(12.1)$

15462 (34.0)

3761 (8.3)

$1348(3.0)$

$19378(42.6)$
$4870(10.7)$

$20322(44.8)$

9943 (21.9)

$2492(5.5)$

7689 (17.0)

\section{Radiation doses ${ }^{e}$}

Mean person-time weighted total

dose lagged by 10 years

(range, SD), mSv

Mean person-time weighted

tritium dose lagged by 10 years

(range, SD), mSv

Solid cancer deaths and person-years by radiation dose category, mSv

\begin{tabular}{|l|c|c|}
\hline$<1$ & $306 / 431363$ & $270 / 486426$ \\
$1-49$ & $118 / 152521$ & $118 / 101,165$ \\
$50-99$ & $23 / 13338$ & $18 / 10230$ \\
$100+$ & $27 / 10758$ & $31 / 15827$ \\
\hline
\end{tabular}

Abbreviations: $\mathrm{AECL}=$ Atomic Energy of Canada Limited; $\mathrm{mSv}=$ millisievert; $\mathrm{NA}=$ not

applicable; SD = standard deviation; SES = socioeconomic status.

${ }^{\mathrm{a}}$ The data from the last study of Canadian workers (Zablotska et al, 2004).

${ }^{\mathbf{b}}$ Current analysis based on the revised and refined data set.

cAECL workers with missing zero recorded doses for 1956-1970 in the NDR, which showed

that they worked for $>1$ year.

${ }^{d} A E C L$ workers listed in the NDR as monitored in non-nuclear facilities only but found in the AECL employment roster for 1956-1981.

${ }^{\mathrm{e}}$ Dose in this and subsequent tables refers to the cumulative person-time weighted lung dose.

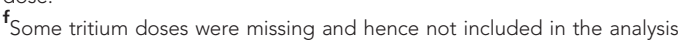

monitored during the year. External doses were penetrating (whole-body) gamma doses expressed as equivalent doses given in millisievert $(\mathrm{mSv})$. Workers with neutrons $(n=15)$ or high internal exposures $(n=10)$ were excluded from the cohort. The latter group included workers with internal doses from various radiation types other than neutrons and tritium, and their doses may not have been estimated systematically in a suitable way for epidemiological analyses.

Internal doses for workers in Canada were primarily from tritium. Tritiated water distributes quickly throughout soft tissues and results in a (nominal) whole-body dose. Tritium doses were assessed using routine urinalysis of workers. The urinalysis measurements were converted into equivalent doses expressed in $\mathrm{mSv}$ using the biokinetic model and dose conversion factors taken from ICRP (International Commission on Radiological Protection (ICRP), 1994, 1997). Quality factors for gamma rays and tritium were assumed equal to 1 . Some pre-1969 records of tritium doses in AECL workers were missing from the NDR (Ashmore et al, 2010) and were not included in the original Canadian study. These were included in the current analysis of the revised cohort and are described in more detail in Supplementary Table S1.

Mortality ascertainment. No changes in the mortality ascertainment (described in detail elsewhere, (Zablotska et al, 2004)) were undertaken. In brief, the cohort was linked to the Historic Summary Tax File (HSTF) and to the Canadian Mortality Data Base (CMDB) to ascertain mortality until the end of 1994. The HSTF includes identifiers and the minimal amount of data required to ascertain the vital status and location of individuals since 1984. The HSTF was used to enhance the mortality linkage by filling in data gaps, to confirm the vital status of the cohort members at the end of the follow-up period and to evaluate the results of the mortality linkage. The CMDB (1950 to present) is based on the vital statistics programme at Statistics Canada, which routinely collects demographic and cause of death information from all provincial and territorial vital statistics registries on all deaths in Canada. Some data are also collected on Canadian residents who died in some states of the United States. Registration of deaths is a legal requirement through the Vital Statistics Acts (or equivalent legislation) in each Canadian province and territory, so reporting is virtually complete. Under-coverage is thought to be minimal ( $\leqslant 1 \%)$ (Goldberg et al, 1993).

Linkage of the worker data to the mortality data was based on a probabilistic approach (Howe and Lindsay, 1981; Howe, 1998), which allows fast and relatively precise linking of the identifying data for a cohort to mortality data from the CMDB. For the present study, manual inspection was used to examine links close to the threshold to resolve any ambiguity or uncertainties. A study comparing the accuracy of ascertaining mortality through computerised record linkage with CMDB found $96.4 \%$ completeness, equivalent to high-quality manual searches (Shannon et al, 1989). Individuals without a social insurance number, who did not link to the HSTF and who did not have a death link in the CMDB had their termination date at work as the last date alive. Vital status ascertainment was complete for $97.6 \%$ of workers and cause of death was known for $99.9 \%$ of deaths.

Statistical analysis. The methods used for this reanalysis were as close as possible to those used for the original Canadian study. Both the original and the revised cohorts included workers monitored in one of the nuclear power plant (NPP) companies $(\mathrm{HQ}, \mathrm{NB}$ or $\mathrm{OH})$ or in the AECL nuclear research and development facility. Individual workers contributed person-years at risk from the date when they had completed 1 year of monitoring until their date of death, last date known alive or 31 December 1994, whichever occurred earlier.

In the categorical analysis, dose was categorised into four categories with cut points similar to those used in the original 
Canadian study $(<1,1-49,50-99, \geqslant 100 \mathrm{mSv})$. The person-year weighted mean total dose in each cell was used in the regression analysis. For comparability with previous studies (Zablotska et al, 2004; Cardis et al, 2007), dose was lagged by 2 years for the analysis of leukaemia and by 10 years for all other cancers. A similar 10year lag was used for whole-body external and tritium doses based on a recent report (Little and Lambert, 2008), although other lag periods were also considered.

For the cancer mortality analyses, the underlying causes of death were recoded from the original International Classification of Disease (ICD) codes in use at the time of death to the ICD, Ninth Revision (ICD-9) (World Health Organization (WHO), 1998). Cancer mortality analyses were conducted for all solid cancers combined, that is, all cancers except leukaemia, lymphoma and multiple myeloma (ICD-9 140.0-199.9), and all leukaemia (204.0208.9). Less detailed analyses were conducted for eight individual cancers with $>10$ deaths. Additional exploratory analyses were conducted for (a) all cancers excluding leukaemia (140.0-203.9) and leukaemia excluding CLL (204.1) to compare with the 15-country study (Cardis et al, 2007), (b) solid cancer excluding lung cancer and/or rectal cancer to verify that the results for solid cancer were not solely dependent on these outcomes and (c) solid cancer by individual facilities and within facilities by start of radiation monitoring to understand the time pattern of radiation risks.

Observed and expected deaths, based on Canadian population death rates (1956-1994) specific for sex, age and calendar year, were used to estimate standardised mortality ratios (SMRs) by means of indirect standardisation. We also conducted internal dose-response analyses without the use of external cancer rates. For these analyses, a linear model was used to estimate excess relative risk per sievert $(\mathrm{ERR} / \mathrm{Sv})$ :

$$
\mathrm{R}_{\mathrm{D}}=\mathrm{R}_{0} *\left(1.0+\beta \operatorname{Dexp}\left(\sum_{\mathrm{i}} \gamma_{\mathrm{i}} z_{\mathrm{i}}\right)\right)
$$

where $R_{D}$ is the rate at dose $D, R_{0}$ is the background rate (stratified to adjust for potential confounders), $\beta$ is the ERR/Sv, $D$ is the cumulative lagged continuous dose, $z_{i}$ are potential effect modifiers, and $\gamma_{i}$ are the corresponding coefficients.

When tritium dose was investigated as a potential risk factor, it was entered into the model simultaneously with the whole-body gamma exposure (both as separate linear terms):

$$
\mathrm{R}_{\mathrm{D}}=\mathrm{R}_{0} *\left(1+\left(\beta_{1} \mathrm{D}_{\text {gamma doses }}+\beta_{2} \mathrm{D}_{\text {tritium doses }}\right) \exp \left(\sum \gamma_{\mathrm{i}} \mathrm{z}_{\mathrm{i}}\right)\right),
$$

Stratification variables for each analysis were selected based both on a priori considerations and empirical results, that is, all variables used in the original Canadian study (sex, attained age, year at risk, duration of monitoring, facility, monitoring status and SES) were not only considered but also verified that they continued to produce a sizable $(\geqslant 10 \%)$ change in the point estimate of the ERR. Person-time tables were cross-classified by all confounders, cumulative radiation dose and monitoring status (still being monitored or no longer monitored). Duration of monitoring was used as a surrogate for duration of employment, to adjust for a healthy worker effect (Gilbert, 1992). Monitoring status was lagged by 5 years to account for individuals who ceased to be monitored, because they had developed cancer, left employment or died within a 5-year period.

We evaluated possible effect modifiers of the dose-response (facility of monitoring, sex, attained age, age at first monitoring and time since first monitoring) using tests of heterogeneity, for categorical variables, and tests of linear trend, for continuous variables. We also evaluated a priori the dose-response by start of monitoring (in 5-year intervals from 1956 to 1994) because of the under-reporting of zero doses to NDR before 1971 (see Supplementary Table S1).
Maximum likelihood point and interval estimates were obtained using the module AMFIT from the computer package EPICURE (Preston et al, 1993). Tests of significance were based on the likelihood ratio test. Because of the form of equation (1), the possible values of $\beta$ are limited by the requirement that the corresponding relative risk should not be negative. If the likelihood being sought for a point or bound estimate did not converge, the minimum value for $\beta$ was given by $-1 / D_{\max }$, where $D_{\max }$ was the maximum dose.

The study was conducted in accordance with accepted ethical practices and was approved by Health Canada's Research Ethics Board.

\section{RESULTS}

Demographic and exposure characteristics of the original and revised cohorts. A total of 607979 person-years at risk were accumulated by the 45468 members of the original cohort with a mean period of follow-up of 13.4 years (not shown). The majority of workers from the original cohort were included in the revised cohort (Table 3). Most workers were male (83.2\%), and except for the lowest dose group $(<1.0 \mathrm{mSv})$, women contributed negligibly to the follow-up (not shown).

Some 513 workers previously included in the original Canadian and 15-country studies were excluded and 361 workers were added as a result of information discovered during evaluation of the AECL facility and NDR dose records (Table 3). The details of these and other data revisions are summarised in Supplementary Table S1. Updates of the revised cohort resulted in the wider dose range compared with the original Canadian study, but mean doses were similar (21.64 vs $19.13 \mathrm{mSv}$ ). Although the cumulative person-time in the revised cohort was larger than in the original cohort, the total number of deaths was reduced, primarily due to exclusion of AECL workers with pre-1956 radiation exposures.

Comparison of the revised cohort with the general Canadian population. Canadian workers (revised cohort) had lower allcause (Supplementary Table S2) and solid cancer (Supplementary Table S3) mortality compared with the similar age-, sex- and calendar-time-adjusted general Canadian population. AECL workers' all-cause mortality and solid cancer mortality were similar to that of all other workers and were significantly lower compared with the general Canadian population. There was no difference between SMRs for all-cause mortality and solid cancer mortality by sex or start of first monitoring. Mortality from all leukaemia, leukaemia excluding CLL, and non-Hodgkin lymphoma was also lower compared with the general Canadian population (Supplementary Table S4). Hodgkin's disease and multiple myeloma had $<10$ deaths in the cohort in 1956-1994, so were not included in the analysis. We noted an increased SMR for all leukaemia among early AECL workers, but it was not statistically significant and was based on a small number of cases.

Dose-response analyses of the revised cohort and comparisons with the results of the original cohort

Solid cancers. AECL workers represented approximately half of follow-up time and deaths from solid cancer in the revised cohort. The majority, however, were in the lowest cumulative dose group $<1 \mathrm{mSv}$ (233136 person-years, 110 deaths, not shown). OH workers had the second largest contribution, with the majority of follow-up time and deaths also in the lowest cumulative dose group (196802 person-years, 138 deaths, not shown). In the categorical analysis of solid cancer mortality in the original and revised cohorts, trends in risk with increasing dose were not statistically significant $(P$-linear trend $=0.11$ and 0.97 , respectively, Figure 1$)$. In the original cohort, there was a significant deficit in risk in the 
lowest positive dose group. In the revised cohort, all relative risk estimates were above unity, and workers with cumulative doses $\geqslant 100 \mathrm{mSv}$ had slightly elevated risks compared with workers with cumulative doses $<1 \mathrm{mSv}$ (relative risk $=1.34,95 \% \mathrm{CI}$ : 0.82, 2.14), but confidence intervals for all dose categories included unity, indicating compatibility with no increase in risks (Figure 1).

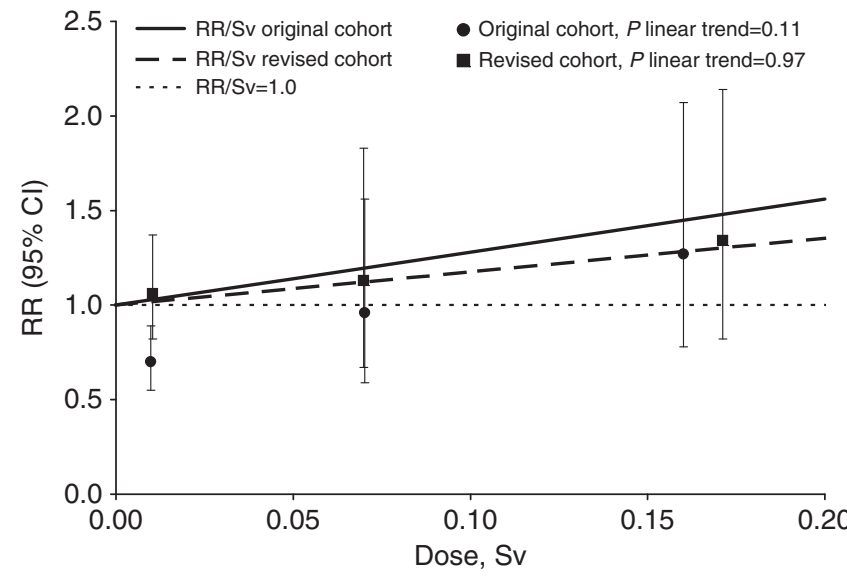

Figure 1. Categorical relative risks and fitted dose-response lines for solid cancer mortality in the original and revised cohorts. Data points and error bars represent category-specific RRs and 95\% Cls for mean recorded dose per category. The fitted linear dose-response was adjusted to pass through the lowest dose category. Dose-response models were adjusted for sex, attained age, socioeconomic status, calendar time and duration of monitoring by stratification.
In analyses using continuous doses, a positive border-line significant increase in risk of solid cancer mortality was estimated in the original Canadian study $(\mathrm{ERR} / \mathrm{Sv}=2.80,95 \% \mathrm{CI}$ : -0.038 , $7.13, P=0.05$, Table 4). A much smaller and statistically nonsignificant increase in risk was estimated in the revised cohort $(\mathrm{ERR} / \mathrm{Sv}=1.77,95 \% \mathrm{CI}:-0.42,5.30, P=0.13)$, a $37 \%$ decrease in the point estimate. Risks of all cancers excluding leukaemia were lower than risks of solid cancer and were also not statistically significant

$(\mathrm{ERR} / \mathrm{Sv}=1.20,95 \% \mathrm{CI}:-0.73,4.33, P=0.27)$. When women were excluded from the cohort ( $11 \%$ of all deaths), the risk estimates remained unchanged (not shown).

The observed elevation in solid cancer mortality radiation risks was only observed in AECL workers (Table 4). Risk estimates for AECL workers were statistically significant and unusually high in both the original $(\mathrm{ERR} / \mathrm{Sv}=4.50,95 \% \mathrm{CI}: 0.60,11.1, P=0.02)$ and revised $(\mathrm{ERR} / \mathrm{Sv}=3.25,95 \% \mathrm{CI}: 0.11,8.85, P=0.04)$ cohorts. All solid cancer mortality radiation risks among workers from the three NPP companies were negative.

Solid cancer mortality radiation risks were statistically significantly increased for AECL workers first monitored before 1960, were lower in magnitude and no longer significant for those first monitored in 1960-1964 and were negative for all other 5-year periods separately and combined starting 1965 (Table 5). No doseresponse of solid cancer mortality was observed when the 27926 workers from the three NPP companies were combined (Table 5), whether first monitored in the early years when facilities became operational (1960 for OH, 1971 for HQ and 1982 for NB) or later.

The observed positive solid cancer radiation dose-response among AECL workers was due to the positive radiation

Table 4. ERR/Sv and $95 \% \mathrm{Cl}$ for mortality from various causes in the original and revised Canadian cohorts of nuclear workers, 1956-1994

\begin{tabular}{|c|c|c|c|c|c|c|}
\hline \multirow[b]{2}{*}{ Cause of death } & \multicolumn{4}{|c|}{ Original } & \multicolumn{2}{|l|}{ Revised } \\
\hline & $\mathrm{N}$ deaths & ERR/Sv $(95 \% \mathrm{Cl})^{\mathrm{a}, \mathrm{b}}$ & $P$-value ${ }^{c}$ & $\mathbf{N}$ deaths & ERR/Sv $(95 \% \mathrm{Cl})^{a, b}$ & $\boldsymbol{P}$-value ${ }^{c}$ \\
\hline Solid cancer & 474 & $2.80(-0.038,7.13)$ & 0.05 & 437 & $1.77(-0.42,5.30)$ & 0.13 \\
\hline $\begin{array}{l}\text { AECL } \\
\text { Hydro-Québec } \\
\text { New Brunswick Power Corporation } \\
\text { Ontario Hydro } \\
\text { Multiple facilities }\end{array}$ & $\begin{array}{c}248 \\
14 \\
9 \\
184 \\
19\end{array}$ & $\begin{aligned} & 4.50(0.60,11.1) \\
- & 4.65(<-4.66,56.5) \\
- & 6.44(<-6.44,445) \\
- & 2.40(<-2.41,4.40) \\
- & 2.02(\mathrm{NE})\end{aligned}$ & $\begin{array}{l}0.02 \\
0.59 \\
0.78 \\
0.30 \\
0.75\end{array}$ & $\begin{array}{c}208 \\
15 \\
9 \\
188 \\
17\end{array}$ & $\begin{array}{c}3.25(0.11,8.85) \\
-4.62(<-4.63,51.6) \\
-6.42(<-6.44,701) \\
-0.13(<-1.90,9.34) \\
\text { NC }\end{array}$ & $\begin{array}{l}0.04 \\
0.62 \\
0.81 \\
0.97\end{array}$ \\
\hline $\begin{array}{l}\text { Cancer of buccal cavity and } \\
\text { pharynx }\end{array}$ & 13 & $7.52(<-2.08,77.6)$ & 0.40 & 12 & $0.91(<-1.47,43.3)$ & 0.87 \\
\hline Esophageal cancer & 14 & $-2.00(<-2.08,55.0)$ & 0.86 & 13 & $-1.45(<-1.47,48.2)$ & 0.88 \\
\hline Colon cancer & 40 & $10.7(<-2.08,48.4)$ & 0.17 & 37 & $14.4(<-1.47,70.9)$ & 0.11 \\
\hline Rectal cancer & 16 & $34.1(1.41,165)$ & 0.03 & 15 & $6.99(<-1.47,64.2)$ & 0.36 \\
\hline Pancreatic cancer & 22 & $-2.03(<-2.08,34.4)$ & 0.59 & 20 & $-1.46(<-1.47,45.2)$ & 0.72 \\
\hline Lung cancer & 183 & $4.34(-0.19,12.7)$ & 0.07 & 174 & $3.13(-0.45,10.4)$ & 0.11 \\
\hline Prostatic cancer & 26 & $0.78(<-2.08,19.2)$ & 0.85 & 22 & $0.43(<-1.47,17.7)$ & 0.91 \\
\hline Brain and other CNS cancer & 25 & $-2.04(<-2.08,8.99)$ & 0.34 & 22 & $-1.45(<-1.47,5.83)$ & 0.32 \\
\hline Other solid cancers & 35 & $-2.04(<-2.08,12.2)$ & 0.42 & 31 & $-1.47(<-1.47,4.26)$ & 0.26 \\
\hline All leukaemia & 22 & $18.9(<-2.08,138)^{d}$ & 0.25 & 21 & $5.06(<-1.49,57.8)^{d}$ & 0.54 \\
\hline Leukaemia excluding CLL & 18 & $52.5(0.205,291)^{d}$ & 0.05 & 17 & $9.79(<-1.49,107)^{d}$ & 0.37 \\
\hline All cancers excluding leukaemia & 509 & $2.37(-0.37,6.60)$ & 0.10 & 468 & $1.20(-0.73,4.33)$ & 0.27 \\
\hline \multicolumn{7}{|c|}{$\begin{array}{l}\text { Abbreviations: } \mathrm{AECL}=\text { Atomic Energy of Canada } L \text { imited; } \mathrm{Cl}=\text { confidence interval; } \mathrm{CLL}=\text { chronic lymphocytic leukaemia; } C N S=\text { central nervous system; } E R R / S v=\text { excess relative risk pe } \\
\text { sievert; } \mathrm{NE}=\text { could not be estimated; } \mathrm{NC}=\text { no convergence after maximum iterations. }\end{array}$} \\
\hline
\end{tabular}


Table 5. Modification of radiation-related risks of mortality from solid cancer by start of nuclear monitoring in the revised cohort of Canadian nuclear workers, 1956-1994

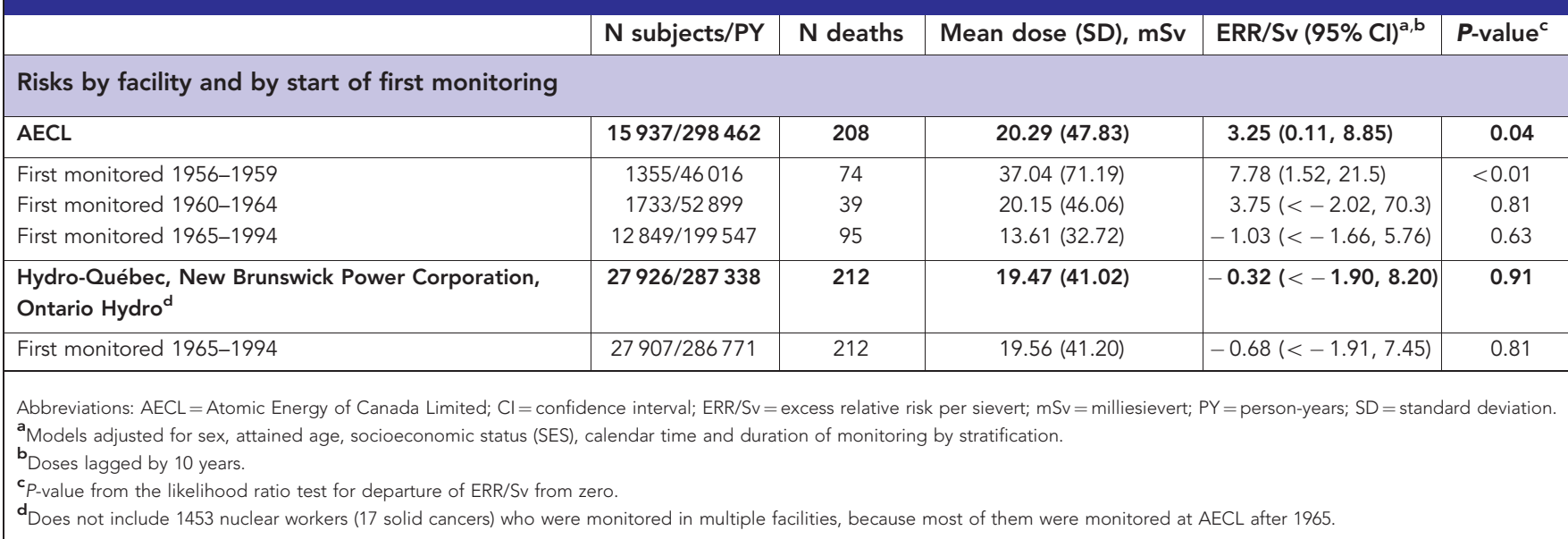

Table 6. Best estimates of radiation-related risks per unit of occupational radiation exposure in the revised Canadian cohort of nuclear workers, 1956-1994

\begin{tabular}{|c|c|c|c|c|c|c|}
\hline \multirow[b]{2}{*}{ Cause of death } & \multicolumn{3}{|c|}{$\begin{array}{l}\text { AECL workers first monitored 1956-1964 } \\
\text { (3088 workers/98915 PY) }\end{array}$} & \multicolumn{3}{|c|}{$\begin{array}{l}\text { All NPP workers and AECL workers first monitored } \\
\text { starting } 1965 \text { (42228 workers/514729 PY) }\end{array}$} \\
\hline & $\mathbf{N}$ deaths & ERR/Sv $(95 \% \mathrm{Cl})^{c}$ & $P$-value ${ }^{b}$ & $\mathbf{N}$ deaths & ERR/Sv $(95 \% \mathrm{Cl})^{c}$ & $\boldsymbol{P}$-value ${ }^{\mathrm{b}}$ \\
\hline All cancers excluding leukaemia & 121 & $6.00(1.02,15.8)$ & $<0.01$ & 347 & $-1.36(<-1.47,1.98)$ & 0.34 \\
\hline Solid cancer & 113 & $7.87(1.88,19.5)$ & $<0.01$ & 324 & $-1.20(<-1.47,2.39)$ & 0.42 \\
\hline All leukaemia & 8 & NC & & 13 & $14.4(<-1.49,146)^{d}$ & 0.28 \\
\hline Leukaemia excluding CLL & 5 & $-1.50(\mathrm{NE})^{\mathrm{d}}$ & 0.85 & 12 & $14.4(<-1.49,146)^{d}$ & 0.28 \\
\hline \multicolumn{7}{|c|}{ 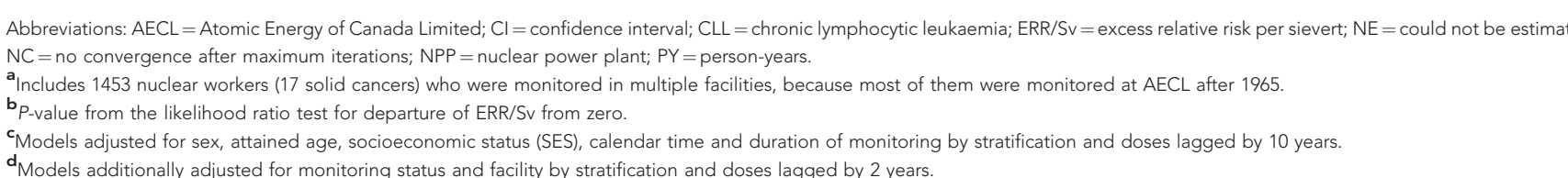 } \\
\hline
\end{tabular}

dose-response observed in 3088 workers first monitored in 1956-1964 $(\mathrm{ERR} / \mathrm{Sv}=7.87,95 \% \mathrm{CI}: 1.88,19.5$, Table 6$)$. The dose-response for the remaining workers from the three NPP companies and AECL workers first monitored starting $1965 \quad(42228$ workers and $514729 \mathrm{PY})$ was negative $(\mathrm{ERR} / \mathrm{Sv}=-1.20,95 \% \mathrm{CI}:<-1.47,2.39)$. A formal test of the difference in slopes between AECL workers first monitored 1956-1964 ( $N=3088$ AECL workers; 113 solid cancer deaths) and all other workers in the revised cohort $(N=42228$ workers; 324 solid cancer deaths) was highly statistically significant ( $P$ heterogeneity $=0.02$, not shown). A significant heterogeneity between the two subcohorts was also observed for all cancers excluding leukaemia ( $P$-heterogeneity $<0.05$, not shown).

Increased dose-related risks of solid cancer mortality among early AECL workers were not modified by age at first monitoring or time since first monitoring (both $P$-linear trend $>0.2$, not shown) or by attained age $(P>0.5)$. Risks per unit of dose for all other Canadian workers remained negative and did not vary by sex ( $P$-heterogeneity $>0.5$, not shown) or age at first monitoring or time since first monitoring (both $P$-linear trend $>0.5$, not shown).

Leukaemia. There were few leukaemia deaths in the original and revised cohorts (22 and 21, respectively) and included only 4 CLL deaths (Table 4). There were increased leukaemia radiation risks in higher dose groups in both cohorts; however, no clear linear trend in risk with increasing dose was observed (not shown).
The radiation risk estimate for all leukaemia $(\mathrm{ERR} / \mathrm{Sv}=5.06$ (95\% CI: $<-1.49,57.8, P=0.54$ ) was much smaller than the estimate without CLL deaths $(\mathrm{ERR} / \mathrm{Sv}=9.79,95 \% \mathrm{CI}:<-1.49$, $107, P=0.37)$ in the revised cohort, but both were not statistically significant. Risks of all leukaemia excluding CLL were negative among early AECL workers but non-significantly increased among the remaining 42228 workers (Table 6).

Various cancer sites. None of the eight individual solid cancer sites with $>10$ deaths showed significant association with dose in the revised cohort (Table 4). The pattern of risks for lung cancer mortality were similar in both cohorts, that is, elevated but not statistically significant and compatible with no increase in risk. Based on 263 non-lung cancer solid cancers, an $\mathrm{ERR} / \mathrm{Sv}=0.80$ (95\% CI: $<-1.47,5.23, P=0.60$ ) was estimated in the revised cohort (not shown). The pattern of risks of solid cancer mortality excluding lung cancer by facility resembled that observed for all solid cancers (i.e., positive although no longer significant risks for early AECL workers and negative risk for workers from all other facilities, not shown).

In the original Canadian study, the only solid cancer outcome with a significantly increased dose-related risk was rectal cancer. In the revised cohort, the risk estimate for rectal cancer was substantially reduced and no longer statistically significant (Table 4). Removal of lung and rectal cancers resulted in a 
substantially reduced risk of solid cancer $(\mathrm{ERR} / \mathrm{Sv}=0.40,95 \% \mathrm{CI}$ : $<-1.47,4.77$, not shown). Examination of individual cancer sites among early AECL workers showed that risks were significantly increased for lung and colon cancer and increased for rectal cancer, which jointly contributed $52 \%$ of all solid cancer deaths.

Radiation-related risks of exposure to tritium. The contribution of tritium to the total whole-body dose in the revised cohort was small (mean tritium dose $=3.02 \mathrm{mSv}$, Table 3 ). Only a small number of workers had tritium doses $\geqslant 50 \mathrm{mSv}(n=809,1.8 \%)$. Tritium doses varied widely by facility and were significantly higher among workers from the three NPP companies compared with AECL workers (mean dose $=4.70$, range: $0-149.32$ and mean dose $=0.64$, range: $0-81.61 \mathrm{mSv}$, respectively).

When tritium doses were added to the model with gamma doses as a second linear term (equation (2)), the fit of the model did not improve $\left(P=0.39\right.$, not shown). We estimated $\mathrm{ERR} / \mathrm{Sv}_{\text {gamma }}$ doses $=2.56(95 \% \mathrm{CI}:-0.11,6.79)$ and $\mathrm{ERR} / \mathrm{Sv}_{\text {tritium doses }}=-4.71$ (95\% CI: $<-5.92,8.58)$ in the model with two separate dose terms. Analyses of lung and other individual solid cancers as well as leukaemia using two linear dose terms showed that risks were due solely to gamma doses and that the addition of tritium doses did not improve the fit of the model (not shown). Despite higher tritium doses for workers from the three NPP companies, the estimate of radiation risk of solid cancer mortality for this group remained negative when workers with non-zero tritium doses were excluded from analyses or when a linear term for tritium dose was added to the model with a linear term for gamma doses (not shown). Estimated risks of solid cancer for AECL workers (both all workers and early workers) remained significant when workers with non-zero tritium doses were excluded from analysis (not shown).

\section{DISCUSSION}

The current reanalysis is based on the verified and revised exposure and cohort information and contains more complete information than either (Gribbin et al, 1993; Cardis et al, 1995) or (Zablotska et al, 2004; Cardis et al, 2005, 2007). It should be considered the most accurate analysis to date of radiation risks among Canadian nuclear workers. The exclusion of AECL workers monitored before 1956, addition of zero-dose records for AECL workers monitored from 1956 to 1971 and other corrections to the original Canadian study (Zablotska et al, 2004) reduced the statistically nonsignificant solid cancer mortality risk estimate from ERR/ $\mathrm{Sv}=2.80$ to $\mathrm{ERR} / \mathrm{Sv}=1.77$ in the current analysis (Table 4). However, we showed that the combined estimate was not an accurate representation of risks per unit of radiation dose for all Canadian nuclear workers in the revised cohort because of identified significant heterogeneity in risks between 3088 AECL workers first monitored in 1956-1964 and 42228 workers at three Canadian NPP companies and post-1964 AECL workers. The estimate of radiation risk of solid cancer for the latter group of Canadian nuclear workers is $\mathrm{ERR} / \mathrm{Sv}=-1.20$ (95\% CI: $<-1.47$, 2.39) and is much lower than either risk estimate excluding $\mathrm{OH}$ workers $(\mathrm{ERR} / \mathrm{Sv}=6.65)$ or including $\mathrm{OH}$ workers (ERR/ $\mathrm{Sv}=3.60$ ) estimated for Canadian workers in the 15-country study (both significant, Table 1); (Cardis et al, 2007). Risks of leukaemia were increased but not statistically significant in the revised cohort. Tritium doses were generally low and analyses of all outcomes showed that risks were due solely to gamma doses.

We observed a significant dose-related increase in risk of solid cancer mortality among early AECL workers first monitored in 1956-1964. The highest attained age and the longest time since first monitoring in this group could provide a better opportunity to detect radiation effects compared with other workers with lower attained age and shorter follow-up. However, increased risks in this group did not vary by time since first monitoring or attained age, and radiation risks of solid cancer were negative for all those first monitored starting 1965. The observed dose-related increase in risk of solid cancer mortality among early AECL workers is also not likely to be due to differential ascertainment of deaths. The SMRs for all-cause mortality and solid cancer mortality among AECL workers, by start of monitoring, were all statistically significantly lower than the Canadian general population. It is also unlikely to be due to missing SES data as risk estimates among early AECL workers were significantly increased both among those with known and those with missing SES information. The increased doserelated risk of solid cancer in this small group of workers was mostly due to a positive radiation dose-response for colon, lung and rectal cancer, but rectal cancer has not been linked to radiation in the A-bomb survivor studies (United Nations Scientific Committee on the Effects of Atomic Radiation (UNSCEAR), 2008; Preston et al, 2010).

Although leukaemia is usually thought to be most strongly related to radiation (United Nations Scientific Committee on the Effects of Atomic Radiation (UNSCEAR), 2008), no dose-response was observed among early AECL workers. A previous study including pre-1956 AECL workers (Gribbin et al, 1993) based on AECL records reported a significantly increased risk of leukaemia, although it was based on a small number of cases and included workers with pre-1956 radiation doses. Significantly increased radiation risks of leukaemia were also reported in other previous Canadian studies (Cardis et al, 1995; Zablotska et al, 2004).

Although the subgroup of 3088 early AECL workers had statistically significantly higher mean doses compared with other AECL workers first monitored starting 1965 or workers from the NPP companies (29.21 vs 13.61 vs $19.47 \mathrm{mSv}$, respectively, $P<0.001$ ), the differences were relatively modest and cannot explain the observed differences in estimated solid cancer mortality risks. Mean doses for early AECL workers were also higher compared with the first study of AECL workers (Gribbin et al, 1993), even though the latter included workers with reconstructed pre-1956 doses (not included in this analysis) (29.21 vs $15.0 \mathrm{mSv}$, respectively). It is not possible to directly compare the two analyses, because dose data for Gribbin et al (1993) study have been lost. This suggests the possibility of missing AECL workers with zero doses before 1971 in the revised cohort. It is likely that the 2871 workers from the reconstructed AECL roster who could not be linked to the NDR had only zero doses and were not reported to the NDR before 1971. If indeed present, this bias would have resulted in the decrease in the number of workers with zero doses and a likely increase in mean cumulative doses. If there was a systematic bias in inclusion of records of AECL employees with zero doses in the NDR in the pre-1971 period, it could explain the differences in solid cancer risk estimates between the studies based on the AECL facility records, which were essentially negative (Gribbin et al, 1993; Cardis et al, 1995), and the studies based on the NDR records (Zablotska et al, 2004; Cardis et al, 2005, 2007). Questions about differences in solid cancer risk estimates between Canadian studies have been raised previously (Gilbert, 2001). Our findings for early AECL workers are the likely reason for the high solid cancer risk estimates in the other NDR-based studies (Ashmore et al, 1998; Sont et al, 2001).

These facts discovered during this reanalysis reinforce our concerns that there remains a data problem in the early AECL workers, most likely missing dose information due to incomplete transfer of AECL dose records to the NDR, as opposed to a true increase in the dose-related risk of solid cancer mortality. Based on our analyses and the identified problem with early AECL dose records, we believe it is not appropriate to use the early AECL data until they can be verified. The CNSC, AECL and NDR discussed the findings of our study for the 3088 early AECL workers and 
agreed on the importance of having accurate and complete records for these workers. At the same time, we have confidence in the data for NPP workers and for AECL workers first monitored starting 1965 as no inconsistencies have been identified during numerous checks (Gale and Doerffer, 2000; Gale, 2002, 2003). The CNSC is starting to make plans to initiate an updated analysis of the Canadian nuclear workers cohort for mortality and cancer incidence. Preparations for an updated analysis will include consideration of the remaining issues with the 1956-1964 AECL workers.

The strengths of the revised Canadian cohort and this study include substantial follow-up (up to 38 years), a large cohort of nuclear workers $(N=45316)$ and reasonably accurate and precise dose information for the majority of workers (93.2\%). Study findings are limited by lack of information on potential confounders, although current analysis improved SES information for a substantial proportion of the cohort. The pattern of risks and the size of dose-related risk estimates of solid cancer excluding lung cancer, a cancer most strongly related to smoking, resembled that of the whole group of solid cancer. Thus, it is unlikely that our results were severely confounded due to missing smoking information. In contrast, in the 15-country study radiation-related risks of lung cancer were significant and very high $(\mathrm{ERR} / \mathrm{Sv}=1.86$, 90\% CI: 0.47, 3.81) (Cardis et al, 2007) and could have biased 15-country study estimates for all cancer excluding leukaemia upward. Thus, there is a strong possibility that the 15-country estimates have been confounded by smoking.

Although analyses for separate facilities and by start of monitoring did not have adequate power to test hypotheses, they provided insight into the nature of the risks of solid cancer observed in this study. As with other studies of occupational exposures of nuclear workers (Thierry-Chef et al, 2007), quality and completeness of dose measurements, especially tritium doses, could have contributed to uncertainties in dose estimation. These errors are expected to be random and would likely result in underestimation of risks. However, previous evaluations of Canadian dosimetry, notwithstanding missing dose records, concluded that measurement error in dosimetry would have had little impact on the results (Thierry-Chef et al, 2002, 2007).

A recent independent study of about 175000 nuclear workers from the United Kingdom (Muirhead et al, 2009) was based on a large number of deaths from all cancer excluding leukaemia (7455 vs 468 in the current study and 5024 in the 15-country study.) The mean cumulative radiation dose among the 42228 Canadian workers was comparable with the UK cohort, and although point estimates for risks of all cancers excluding leukaemia were quite different $(\mathrm{ERR} / \mathrm{Sv}=-1.36,95 \% \mathrm{CI}:<-1.47,1.98$ and $\mathrm{ERR} /$ $\mathrm{Sv}=0.275$, 90\% CI: $0.02,0.56$, respectively), the confidence intervals overlapped, suggesting compatibility. Both were compatible with the risk estimated for male A-bomb survivors exposed at age 35 years $(\mathrm{ERR} / \mathrm{Sv}=0.32,90 \% \mathrm{CI}: 0.07,0.47)$ (Cardis et al, 2007).

It is important to consider the potential effects of using verified and revised exposure and cohort information from the current study on the pooled estimate of risk from all cancers excluding leukaemia in the 15-country study. The Canadian cohort was a major factor behind the finding of a statistically significant dose-related increase in risk for all cancers excluding leukaemia mortality (Cardis et al, $2005,2007)$. Our review of the differences in analytical strategies between the original Canadian cohort study (Zablotska et al, 2004) and the 15-country study (Cardis et al, 2007) showed that the unusually high dose-related cancer risk estimate in the latter study for Canada was most likely driven by a single facility, AECL. Our analysis of the revised cohort and exposure data suggests that a small group of 3088 early AECL workers first monitored 1956-1964 had a consistent and significant dose-related risk of solid cancer mortality but not leukaemia. The findings of this study suggest that the revised Canadian cohort, with the exclusion of early AECL workers, would likely have an important effect on the pooled risk estimate of radiation-related risks of all cancer excluding leukaemia by substantially reducing the size of the point estimate and its significance.

In summary, the present study provides the most accurate data to date on mortality in the cohort of Canadian nuclear workers. Some 42228 workers from Ontario Hydro, Hydro-Québec and New Brunswick Power Corporation NPPs and AECL workers first monitored starting 1965 had no dose-related increase in risk of solid cancer mortality due to radiation exposure. A small group of 3088 AECL workers first monitored in 1956-1964 showed a consistent and significant dose-related risk of solid cancer mortality but not leukaemia. Although a genuine difference in response between the two groups cannot be ruled out, inconsistencies in dose information for AECL in that early period appear to be causing a systematic error that cannot be explained at this time. Overall, the results of analyses of the revised Canadian data are compatible with the current radiation risk estimates from low-dose radiation exposures that form the basis of radiation protection standards.

\section{ACKNOWLEDGEMENTS}

We would like to thank Dr Patrick Ashmore, Dr Norman Gentner, Dr Richard Osborne, Dr John Boice, Jr and Dr Richard Wakeford for their external review of the preliminary report on Canadian reanalysis submitted to the Canadian Nuclear Safety Commission (CNSC). We are very grateful to Dr Ethel Gilbert for a careful review of the manuscript and helpful discussions and to Dr John Boice, Jr for a thorough review of several versions of the manuscript. We thank Dr Ashmore for his preliminary work on the missing zero-dose records and Statistics Canada for relinking the additional records to the CMDB. We thank Dr David Whillans for his help in providing SES data for Ontario Hydro workers and his advice and review; especially regarding the tritium dosimetry. Finally, we thank IARC and Dr Elizabeth Cardis, currently at CREAL, Spain for providing us with the Canadian cohort analysis file used in the 15-country pooled study.

Funding for this study was provided by the CNSC. Dr Zablotska's effort was additionally supported by the National Institutes of Health, the National Cancer Institute grant CA132918. The CNSC was established under the Nuclear Safety and Control Act (NSCA). The CNSC, as a quasi-judicial administrative tribunal, is independent of all political, governmental or private sector influence. Section 9 (b) of the NSCA provides the mandate to disseminate objective scientific, technical and regulatory information concerning the effects of nuclear energy and nuclear substances on the health and safety of persons.

CONFLICT OF INTEREST

The authors declare no conflict of interest.

\section{REFERENCES}

Ashmore JP, Gentner NE, Osborne RV (2010) Incomplete data on the Canadian cohort may have affected the results of the study by the International Agency for Research on Cancer on the radiogenic cancer risk among nuclear industry workers in 15 countries. J Radiol Prot 30(2): 121-129.

Ashmore JP, Krewski D, Zielinski JM (1997) Protocol for a cohort mortality study of occupational radiation exposure based on the National Dose Registry of Canada. Eur J Cancer 33(Suppl. 3): S10-S21.

Ashmore JP, Krewski D, Zielinski JM, Jiang H, Semenciw R, Band PR (1998) First analysis of mortality and occupational radiation exposure based on the National Dose Registry of Canada. Am J Epidemiol 148(6): 564-574. 
Boice JD (2010) Uncertainties in studies of low statistical power. J Radiol Prot 30(2): 115-120.

Cardis E, Gilbert ES, Carpenter L, Howe G, Kato I, Armstrong BK, Beral V, Cowper G, Douglas A, Fix J et al. (1995) Effects of low doses and low dose rates of external ionizing radiation: cancer mortality among nuclear industry workers in three countries. Radiat Res 142(2): 117-132.

Cardis E, Vrijheid M, Blettner M, Gilbert E, Hakama M, Hill C, Howe G, Kaldor J, Muirhead CR, Schubauer-Berigan M, Yoshimura T, Bermann F, Cowper G, Fix J, Hacker C, Heinmiller B, Marshall M, Thierry-Chef I, Utterback D, Ahn YO, Amoros E, Ashmore P, Auvinen A, Bae JM, Bernar J, Biau A, Combalot E, Deboodt P, Diez Sacristan A, Eklof M, Engels H, Engholm G, Gulis G, Habib RR, Holan K, Hyvonen H, Kerekes A, Kurtinaitis J, Malker H, Martuzzi M, Mastauskas A, Monnet A, Moser M, Pearce MS, Richardson DB, Rodriguez-Artalejo F, Rogel A, Tardy H, Telle-Lamberton M, Turai I, Usel M, Veress K (2007) The 15-Country Collaborative Study of Cancer Risk among Radiation Workers in the Nuclear Industry: estimates of radiation-related cancer risks. Radiat Res 167(4): 396-416.

Cardis E, Vrijheid M, Blettner M, Gilbert E, Hakama M, Hill C, Howe G, Kaldor J, Muirhead CR, Schubauer-Berigan M, Yoshimura T, Bermann F, Cowper G, Fix J, Hacker C, Heinmiller B, Marshall M, Thierry-Chef I, Utterback D, Ahn YO, Amoros E, Ashmore P, Auvinen A, Bae JM, Solano JB, Biau A, Combalot E, Deboodt P, Diez Sacristan A, Eklof M, Engels H, Engholm G, Gulis G, Habib R, Holan K, Hyvonen H, Kerekes A, Kurtinaitis J, Malker H, Martuzzi M, Mastauskas A, Monnet A, Moser M, Pearce MS, Richardson DB, Rodriguez-Artalejo F, Rogel A, Tardy H, Telle-Lamberton M, Turai I, Usel M, Veress K (2005) Risk of cancer after low doses of ionising radiation: retrospective cohort study in 15 countries. BMJ 331(7508): 77.

Gale KL (2002) Validation and use of National Dose Registry records: Phase 3 report for Ontario Power Generation Toronto, ON, USA. Report no. COG 01-193.

Gale KL (2003) National Dose Registry data inter-comparison: Review of the study. Toronto, ON, USA. Report no. COG 02-3019.

Gale KL, Doerffer K (2000) Validation and use of the National Dose Registry records: Phase 3 Chalk River, ON, USA. Report no. COG-99-069, RC-2449.

Gilbert ES (1992) Leukemia among nuclear workers with protracted exposure to low-dose ionizing radiation. Epidemiology 3(3): 275-276.

Gilbert ES (2001) Invited commentary: studies of workers exposed to low doses of radiation. Am J Epidemiol 153(4): 319-322; discussion 323-4.

Goldberg MS, Carpenter M, Theriault G, Fair M (1993) The accuracy of ascertaining vital status in a historical cohort study of synthetic textiles workers using computerized record linkage to the Canadian Mortality Data Base. Can J Public Health 84(3): 201-204.

Gribbin MA, Weeks JL, Howe GR (1993) Cancer mortality (1956-1985) among male employees of Atomic Energy of Canada Limited with respect to occupational exposure to external low- linear-energy-transfer ionizing radiation. Radiat Res 133(3): 375-380.

Howe GR (1998) Use of computerized record linkage in cohort studies. Epidemiol Rev 20(1): 112-121.

Howe GR, Chiarelli AM, Lindsay JP (1988) Components and modifiers of the healthy worker effect: evidence from three occupational cohorts and implications for industrial compensation. Am J Epidemiol 128(6): 1364-1375.

Howe GR, Lindsay J (1981) A generalized iterative record linkage computer system for use in medical follow-up studies. Comput Biomed Res 14(4): $327-340$.

International Agency for Research on Cancer (IARC) (2000) Monographs on the evaluation of carcinogenic risks to humans. Ionizing radiation, part 1 $X$-ray and gamma-radiation, and neutrons. World Health Organization: Lyon, France, International Agency for Research on Cancer. Report no Volume 75.

International Agency for Research on Cancer (IARC) (2012) Monographs on the evaluation of carcinogenic risks to humans. A Review of Human Carcinogens. D. Radiation. World Health Organization: Lyon, France, International Agency for Research on Cancer. Report no Volume 100 (D).
International Commission on Radiological Protection (ICRP) (1994) Dose Coefficients for Intakes of Radionuclides by Workers. Annals of the ICRP 24 (4). Pergamon Press: Oxford UK. Report no.: ICRP Publication 68.

International Commission on Radiological Protection (ICRP) (1997) Individual Monitoring for Internal Exposure of Workers. Annals of the ICRP 27 (3-4). Pergamon Press: Oxford, Report no.: ICRP Publication 78.

Little MP, Lambert BE (2008) Systematic review of experimental studies on the relative biological effectiveness of tritium. Radiat Environ Biophys 47(1): 71-93.

Little MP, Wakeford R (2008) Systematic review of epidemiological studies of exposure to tritium. J Radiol Prot 28(1): 9-32.

Muirhead CR, O’Hagan JA, Haylock RG, Phillipson MA, Willcock T, Berridge GL, Zhang W (2009) Mortality and cancer incidence following occupational radiation exposure: third analysis of the National Registry for Radiation Workers. Br J Cancer 100(1): 206-212.

National Dose Registry (NDR) (2007) 2006 Report on Occupational Radiation Exposures in Canada: Ministry of Health Canada.

National Research Council (NRC) (2006) Committee to Assess Health Risks from Exposure to Low Levels of Ionizing Radiation. Health risks from exposure to low levels of ionizing radiation. BEIR VII Phase 2. National Academies Press: Washington, DC, USA.

Preston DL, Krestinina LY, Sokolnikov ME, Ron E, Davis FG, Ostroumova EV, Gilbert ES (2010) How much can we say about site-specific cancer radiation risks? Radiat Res 174(6): 816-824.

Preston DL, Lubin JH, Pierce DA, McConney ME (1993) EPICURE User's guide. Hirosoft International Corporation: Seattle, WA, USA.

Shannon HS, Jamieson E, Walsh C, Julian JA, Fair ME, Buffet A (1989) Comparison of individual follow-up and computerized record linkage using the Canadian Mortality Data Base. Can J Public Health 80(1): 54-57.

Sont WN, Zielinski JM, Ashmore JP, Jiang H, Krewski D, Fair ME, Band PR, Letourneau EG (2001) First analysis of cancer incidence and occupational radiation exposure based on the National Dose Registry of Canada. Am J Epidemiol 153(4): 309-318.

Thierry-Chef I, Marshall M, Fix JJ, Bermann F, Gilbert ES, Hacker C, Heinmiller B, Murray W, Pearce MS, Utterback D, Bernar K, Deboodt P, Eklof M, Griciene B, Holan K, Hyvonen H, Kerekes A, Lee MC, Moser M, Pernicka F, Cardis E (2007) The 15-Country Collaborative Study of Cancer Risk among Radiation Workers in the Nuclear Industry: study of errors in dosimetry. Radiat Res 167(4): 380-395.

Thierry-Chef I, Pernicka F, Marshall M, Cardis E, Andreo P (2002) Study of a selection of 10 historical types of dosemeter: variation of the response to $\mathrm{Hp}(10)$ with photon energy and geometry of exposure. Radiat Prot Dosimetry 102(2): 101-113.

United Nations Scientific Committee on the Effects of Atomic Radiation (UNSCEAR) (2008) Sources and Effects of Ionizing Radiation. UNSCEAR 2006 Report to the General Assembly with Scientific Annexes. Volume I, Annex A: Epidemiological studies of radiation and cancer. UNSCEAR: New York, USA.

Vrijheid M, Cardis E, Blettner M, Gilbert E, Hakama M, Hill C, Howe G, Kaldor J, Muirhead CR, Schubauer-Berigan M, Yoshimura T, Ahn YO, Ashmore P, Auvinen A, Bae JM, Engels H, Gulis G, Habib RR, Hosoda Y, Kurtinaitis J, Malker H, Moser M, Rodriguez-Artalejo F, Rogel A, Tardy H, Telle-Lamberton M, Turai I, Usel M, Veress K (2007) The 15-Country Collaborative Study of Cancer Risk Among Radiation Workers in the Nuclear Industry: design, epidemiological methods and descriptive results. Radiat Res 167(4): 361-379.

Wakeford R (2005) Cancer risk among nuclear workers. J Radiol Prot 25(3): 225-228.

Wakeford R (2009) Radiation in the workplace-a review of studies of the risks of occupational exposure to ionising radiation. J Radiol Prot 29(2A): A61-A79.

World Health Organization (WHO) (1998) International Classification of Diseases, Ninth Revision (ICD-9). WHO: Geneva, Switzerland.

Zablotska LB, Ashmore JP, Howe GR (2004) Analysis of mortality among canadian nuclear power industry workers after chronic low-dose exposure to ionizing radiation. Radiat Res 161(6): 633-641.

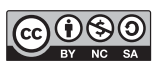
This work is licensed under the Creative Commons Attribution-NonCommercial-Share Alike 3.0 Unported License. To view a copy of this license, visit http://creativecommons. org/licenses/by-nc-sa/3.0/

Supplementary Information accompanies this paper on British Journal of Cancer website (http://www.nature.com/bjc) 